ORIGINAL ARTICLE

\title{
Is hydronephrosis a risk factor for complications in conventional percutaneous nephrolithotomy?
}

\author{
Fakhir Yousuf', Salman el Khalid², Abdul Wasy Mahmood ${ }^{3}$, Zafar Iqbal', Waqar Hassan ${ }^{5}$, Shakeel Haseeb Uddin Siddique ${ }^{6}$
}

Article Citation: Yousuf F, Salman el Khalid, Mahmood AW, Iqbal Z, Hassan W, Siddique S Haseeb Uddin. Is hydronephrosis a risk factor for complications in conventional percutaneous nephrolithotomy? Professional Med J 2022; 29(1):110-115.

https://doi.org/10.29309/TPMJ/2022.29.01.6443

\begin{abstract}
Objective: To assess Hydronephrosis as a Risk Factor for complications in Conventional Percutaneous Nephrolithotomy. Study Design: Cross Sectional Descriptive study. Setting: Kidney Centre Post Graduate Training Centre, Karachi. Period: January to December 2020. Material \& Methods: This study was done to know post-operative complications including bleeding, infection, and incomplete stone clearance in patients with or without hydronephrosis undergoing percutaneous nephrolithotomy. After applying the inclusion/ exclusion criteria it was found that the patients with hydronephrosis had less bleeding as compared to the no hydronephrosis group. In the same way, they also had fewer nephrostomy tubes placed, and chest drain insertion. All other complications were approximately the same in each group. Patients were selected using non-probability consecutive sampling technique. Percentage and frequencies were determined for quantitative variables. Mean and standard deviation were determined for quantitative variables. Results: Total 300 cases were studied fulfilling inclusion criteria. There were $70.07 \%$ male and $29.3 \%$ female cases. Age range of the patients was 1860 years. There were $52.7 \%$ cases with hydronephrosis, placed in one group and $47.3 \%$ cases were without hydronephrosis placed in other group. Most common complication was postoperative bleeding reported in $48.9 \%$ cases with hydronephrosis as compared to $56.2 \%$ cases without hydronephrosis. Mean operative time was $115.7 \pm 41.9$ minutes in patients with hydronephrosis and $135 \pm 35.4$ minutes in patients without hydronephrosis. Conclusion: Patients with hydronephrosis experienced less postoperative complications, after PCNL as compared to those without hydronephrosis.
\end{abstract}

Key words: Hydronephrosis, Hydrothorax, Pneumothorax, Percutaneous Nephrolithotomy, Urolithiasis.

\section{INTRODUCTION}

Renal stone disease is very common and affect $0.13 \%$ population. Percutaneous nephrolithotomy $(\mathrm{PCNL})$ remains an integral part of treatment for large complex renal stones. Although it is widely used nowadays, postoperative complication rates are still relatively higher. An overall complication rate of $20.5 \%$ has been reported after PCNL ${ }^{1}$, namely fever and bleeding (most frequent), urinary leakage, hydrothorax, hematuria, urinary tract infection, pelvic perforation, and urinary fistula. Frequency of post-operative bleeding after PCNL can range from 0 to $20 \%$. PCNL is used for large renal stones. Choice of treatment in renal stones depends on stone size, availability of equipment, any additional procedure required and patient preference ${ }^{2}$

Hydronephrosis, defined as dilatation of the pelvicalyceal system because of failure of urine excretion. It is mainly sub-grouped into obstructive or non-obstructive Hydronephrosis. ${ }^{3}$ Obstructive hydronephrosis is usually caused by urinary stones, blood clots, uretero-pelvic junction (UPJ) obstruction, stricture or external compression by tumor, fibrosis or others. The obstruction may be acute or chronic, unilateral or bilateral, partial or complete. On the other hand, Non-obstructive hydronephrosis is caused by reflux, residual or others. $^{4}$
1. MBBS, MRCS (GLAS), FCPS, Registrar Urology, The Kidney Centre Post Graduate Training Centre, Karachi.

2. MBBS, FRCS, FCPS, Associate Professor Urology, The Kidney Centre Post Graduate Training Centre, Karachi.

3. FCPS (Urology), Post Graduate Resident, The Kidney Centre Post Graduate Training Centre, Karachi.

4. MBBS, Research Volunteer, The Kidney Centre Post Graduate Training Centre, Karachi.

5. MBBS, FCPS (Urology), Registrar Urology, The Kidney Centre Post Graduate Training Centre, Karachi.

6. MBBS, FCPS (Urology), Registrar Urology, The Kidney Centre Post Graduate Training Centre, Karachi.

\author{
Correspondence Address: \\ Dr Fakhir Yousuf \\ Department of Urology \\ The Kidney Centre Post Graduate Training \\ Centre, Karachi \\ yousuf58@hotmail.com
}

Article received on:

22/02/2021

Accepted for publication: 
The Society of Fetal Urology (SFU) grading system is used commonly to grade hydronephrosis in all age groups. There is a lack of data regarding hydronephrosis as a risk factor for complications after percutaneous nephrolithotomy (PCNL). The significance of hydronephrosis on surgical outcomes, after PCNL, is not well established. Previous studies demonstrate conflicting results regarding this notion. For example Hydronephrosisis associated with a low number of complications after PCNL. ${ }^{6}$ On the other hand association of Hydronephrosis with a higher residual stone $^{7}$ Urosepsis has been reported a common complication due to infection after PCNL. Most of the time urosepsis is not diagnosed clinically and remains untreated. It is associated with urinary tract infection accounting $5 \%$ of all sepsis types. ${ }^{8}$ New guidelines mention urosepsis a medical emergency which need to be treated promptly by giving intravenous fluids to manage hemodynamic status and suitable intravenous antibiotics. ${ }^{9}$

Bleeding during PCNL is a major complication reported in $0-20 \%$ cases. Many studies have tried to evaluate risk factors of bleeding. Presence and absence of hydronephrosis is a main risk factor determining bleeding during the procedure. Renal cortex in patients without hydronephrosis is thick and space in renal calyces is minimum, hence making PCNL difficult for urologists with increased risk of renal hemorrhage. Postoperative fever and sepsis are other complications after percutaneous nephrolithotomy. According to a report ever occurs in $21-39 \%$ cases and urosepsis occurs in $0.3-9.3 \%$ cases. Urosepsis is a life threatening condition with high mortality rate. ${ }^{10}$

Therefore, in this study, we aim to analyze various known post-operative complications including bleeding, infection, incomplete stone clearance, etc., according to the presence or absence of hydronephrosis in percutaneous nephrolithotomy
(PCNL) patients.

Previously such study has not been conducted in our center; therefore, the results will help in improving future surgical practices and minimizing post-operative surgical complications.

\section{MATERIAL \& METHODS}

A retrospective study was conducted at The Kidney Centre Post Graduate Training Centre, Karachi. Patients operated during twelve months duration from January to December 2020. Ethical approval was taken from the institutional review board (104-URD-072020). Data of the patients was taken from the hospital records. To assess the significance of hydronephrosis causing postoperative complications after PCNL. Inclusion criteria included age 18-60 years, single stone size 1 to $3 \mathrm{cms}$, post- PCNL 20-22 Fr, Radioopaque stones, Post PCNL complete clearance. Exclusion criteria was age more than 60 years or less than 18 years, Staghorn stone or multiple, radiolucent stone, Partial clearance after PCNL.

Two Independent Proportions (Null Case) Power Analysis

Numeric Results of Tests Based on the Difference: $\mathrm{P} 1$ - P2

H0: P1-P2=0. H1: P1-P2=D1<>0. Test Statistic: $Z$ test with pooled variance

Note: Exact results based on the binomial were only calculated when both $\mathrm{N} 1$ and $\mathrm{N} 2$ were less than 100.

We calculated the sample size from the PASS II sample size calculator. The number of patients required 82 patients in each group to find the difference in para and postoperative complications between hydronephrosis and without hydronephrosis groups.

\begin{tabular}{|lllllllllll|}
\hline Sample & Sample & Prop|H1 & Prop & & & & & \\
& Size & Size & Grp 1 or & Grp 2 or & Diff & Diff & & & \\
& Grp 1 & Grp 2 & Treatment & Control & if H0 & if H1 & Target & Actual & \\
Power & N1 & N2 & P1 & P2 & D0 & D1 & Alpha & Alpha & Beta \\
0.8012 & 82 & 82 & 0.2840 & 0.1130 & 0.0000 & 0.1710 & 0.0500 & 0.0495 & 0.1988 \\
\hline
\end{tabular}


Analysis plan: Data was entered and analyzed on SPSS 21. Cleaning and coding of data were done before analysis. Mean and Standard deviation was calculated for continuous variables like BMI, stone size and Hemoglobin levels. Frequency and percentages were calculated for all categorical data like Gender and group status of the patient. Differences between groups were assessed by t-test or Mann Whiteney test for continuous variables and by Chi-square or Fisher exact test in case of categorical parameters. Statistical significance was considered at P-value $<0.05$.

\section{RESULTS}

We enrolled 300 patients in our study in which 212 (70.07\%) were male while 88 (29.3\%) were female. Patients with hydronephrosis comprise 157 patients (52.7\%) in our research, as compared to 143 patients (47.3\%) without hydronephrosis. Most of the patients with hydronephrosis had grade 3 hydronephrosis, 62(39.5\%). (Table-l) when we observed the association between postoperative complications with 2 study groups, we found that significant bleeding, nephrostomy tube insertion, and chest drain were significantly associated with the absence of hydronephrosis. The patients with hydronephrosis had less bleeding as compared to the no hydronephrosis group [64 (48.9\%) +82 (56.2\%)] respectively with a p-value of 0.004 . similarly, they also had fewer nephrostomy tubes placed [111 (48.9\% vs 116 (51.1\%)] and chest drain [8 (30.8\%) vs $18(69.2 \%)]$. All other complications were approximately the same in each group. None of the patients died of hydrothorax or urinary fistula.

\begin{tabular}{|c|c|c|c|c|c|c|c|}
\hline \multirow{3}{*}{$\begin{array}{l}\text { Variables } \\
\text { Age (years) }\end{array}$} & \multicolumn{6}{|c|}{ Mean \pm Std \& Median, IQR - Minimum- Maximum } & \multirow{3}{*}{$\begin{array}{c}\begin{array}{c}\text { P- } \\
\text { Value }\end{array} \\
0.246\end{array}$} \\
\hline & \multicolumn{3}{|c|}{ Patients With Hydronephrosi } & \multicolumn{3}{|c|}{ Patients Without Hydronephrosis } & \\
\hline & $41 \pm 14.4 \& 41,24$ & 18 & 67 & $39.2 \pm 14 \& 40,22$ & 18 & 66 & \\
\hline Weight (kg) & $70.2 \pm 14.1 \& 69,24.5$ & 46 & 104 & $67.7 \pm 14.4 \& 68,27$ & 46 & 98 & 0.116 \\
\hline Height (cm) & $160.4 \pm 9.8 \& 160,10$ & 140 & 180 & $160.3 \pm 8.8 \& 160,10$ & 140 & 180 & 0.625 \\
\hline Stone size (mm) & $21.8 \pm 6.8 \& 20,8$ & 10 & 40 & $20.9 \pm 7 \& 20,10$ & 10 & 40 & 0.182 \\
\hline Pre-operative $\mathrm{Hb}(\mathrm{g} / \mathrm{dl})$ & $13.4 \pm 1.2 \& 13.4,1.8$ & 10.3 & 16.3 & $13.2 \pm 1.1 \& 13.2,1.8$ & 10.9 & 16.3 & 0.13 \\
\hline Post-operative Hb (g/dl) & $11.2 \pm 1.2 \& 11.3,1.5$ & 8 & 14.5 & $11.1 \pm 1.1 \& 11.2,1.3$ & 8.4 & 14.2 & 0.284 \\
\hline Difference in $\mathrm{Hb}(\mathrm{g} / \mathrm{dl})$ & $2.2 \pm 0.75 \& 2.1,0.9$ & 0.5 & 4.5 & $2.1 \pm 0.6 \& 2.1,0.8$ & 0.4 & 3.7 & 0.752 \\
\hline
\end{tabular}

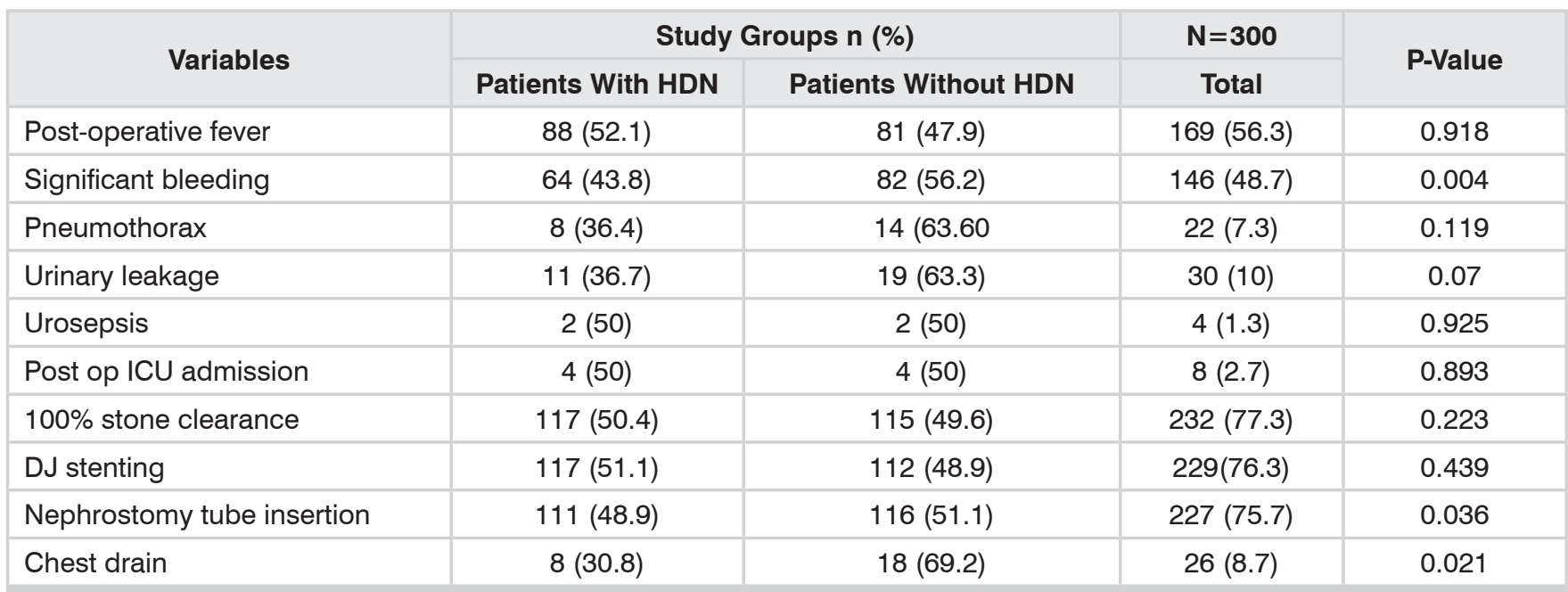

Table-II. Association of hydronephrosis with post-operative complication of patients. 
All baseline demographic data and clinical parameters were the same in both groups, $(p>$ $0.05)$. There was no significant difference in the drop between the 2 groups $(2.2+0.75$ and $2.1+0.6)$, the $p$-value is 0.752 . On the other hand, operative time was significantly decreased with patients with hydronephrosis $(115.7+41.9$ and $135+34.5)$ respectively.

\section{DISCUSSION}

PCNL surgeries have been a norm for patients to remain under observation postoperatively. The main reasons for this assessing patients for hemorrhage, observing for infection whether requires antibiotics treatment, imaging to exclude any residual stones, and ensuring adequate drainage of kidneys to prevent urinary stasis. ${ }^{10}$ According to studies success rate of PCNL is more than $90 \%$ and postoperative bleeding is its common and serious complication which most of the times can be treated conservatively while sometimes (in $0.8 \%$ cases) arteriography and selective embolization is required. ${ }^{11,12}$

A study conducted in Korea by Kim et al reported that patients without hydronephrosis undergoing PCNL required longer hospital stay, prolonged operating time, lower stone clearance rate and higher blood transfusion rate due to bleeding complications as compared to the patients with hydronephrosis. ${ }^{13}$ In our study, postoperative bleeding was observed in 64 (40.7\%) patients who had hydronephrosis in contrast to 82 (57.3\%) patients who had not had hydronephrosis, and the $p$-value was 0.004 .

Wang et al studied outcomes of PCNL in 207 cases reported higher level of difficulty in accessing stone and more complications among those patients having staghorn stone $(p=0.032)$, previous ipsilateral open nephrolithotomy $(p=0.026)$ and stone in lower pole of kidney $(p=0.039) .{ }^{14}$ In our study patients with staghorn stones or previously operated for nephrolithotomy ipsilateral were not included in the study.

According to Meng et al factors influencing postoperative bleeding after PCNL include operative time $(p=0.005)$, stone size $(p=0.001)$, type of stone $(p=0.001)$ and degree of hydronephrosis $(p=0.001) .{ }^{15}$ Similarly we found in our study stone size $(p=0.182)$ and operative time $(p<0.001)$ important factors determining postoperative bleeding.

Pimratana et al studied outcomes of hydronephrosis in PCNL in 85 cases. In their study mean stone size was $48.2 \pm 16.6 \mathrm{~mm}$ and mean body mass index was $23.7 \pm 3.7 \mathrm{~kg} / \mathrm{m}^{2}$. Success rate of renal access was $98.8 \%$ and stone free rate was $64.7 \%$. Complications reported were failure of stone access in $1.17 \%$ cases, need of blood transfusion in $7.1 \%$, postoperative fever in $30.6 \%$ and urosepsis in $2.6 \%$ cases. ${ }^{16}$ In our study, urosepsis was observed in both groups with 2 patients in each group (1.3\%) with a p-value of 0.925 . Postoperative ICU admission was noted in 4 patients in each group (2.7\%) with a p-value of 0.893.8. Postoperative fever was reported in $52.1 \%$ cases with hydronephrosis and $47.9 \%$ cases without hydronephrosis. Mean stone size was $21.8 \pm 6.8 \mathrm{~mm}$ and $20.9 \pm 7 \mathrm{~mm}$ in both groups of patients with hydronephrosis and without hydronephrosis.

A study conducted in USA concluded incidence of silent hydronephrosis after PCNL in $16 \%$ cases which remains undiagnosed or untreated in $2 \%$ cases, usually due to residual stone or stricture formation. Majority of patients do not need any treatment for silent hydronephrosis and it is eventually resolved. Postoperative ultrasound should be done after PCNL to see hydronephrosis due to silent obstruction following PCNL. ${ }^{17}$ According to a study conducted in China, percutaneous nephrolithotomy was done in 192 patients with severe hydronephrosis and outcomes were reported as overall stone free rate was $86.5 \%$ and overall complication rate was $18.2 \%$ include. Common complications were ureteral stricture in 5.2\% cases and recurrence of stone in $2 \%$ cases. Most of the reported complications were minor. ${ }^{18}$

According to a study conducted on 246 patients, postoperative complications after PCNL were reported in $41.06 \%$ cases and out of them only 9.35\% cases experienced major complications. 
In Age, gender, body mass index, presenting complaints and history of previous surgery in their study cases were not determining rate of postoperative complications. ${ }^{19}$

A study conducted in India reported stone clearance rate of $85.7 \%$ in PCNL via single tract while additional tracts were made in $14.29 \%$ cases. Postoperative urinary tract infection was reported in $6.6 \%$ cases. $^{20}$

The incidence of Pneumothorax, hydrothorax, and hemothorax are very rare post PCNL with an incidence of less than $2 \%$. Pneumothorax and hydrothorax occur due to rupture of pleura. Supracostal (above 12th rib) approach and leftsided procedures have been associated with increased risk of thoracic complications. ${ }^{21-23}$ In our study, Patients having hydronephrosis who had post-op pneumothorax complications were recorded as $8(36.4 \%)$ as opposed to incidence of $63.6 \%$ among patients without hydronephrosis. The $\mathrm{p}$-value was 0.119 .

This study aims to compare post-operative complications such as fever, Urosepsis, pneumothorax, bleeding in a patient with hydronephrosis, and without hydronephrosis after the PCNL. All other complications were approximately the same in each group. There are some limitations to the current study: not including patients aged more than 60 years or less than 18 years, Staghorn stones or multiple, Radiolucent stone, Partial clearance after PCNL. The outcome could be different if the limitations have been included.

\section{CONCLUSION}

In this study we found out that patients with hydronephrosis had less bleeding as compared to no hydronephrosis group, similarly, they also had fewer nephrostomy tubes and chest drain insertion. All other complications were approximately the same in each group.

Copyright@ 29 Apr, 2021.

\section{REFERENCES}

1. Alshoabi SA. Association between grades of Hydronephrosis and detection of urinary stones by ultrasound imaging. Pakistan journal of medical sciences. 2018 Jul; 34(4):955. https://dx.doi. org/10.12669\%2Fpjms.344.14602.

2. Amri M, Naouar S, Khalifa B, Hmidi N, Braiek S, ElKamel $R$. Predictive factors of bleeding and fever after percutaneous nephrolithotomy. La Tunisie medicale. 2019 May 1; 97(5):667-74.

3. Kim HY, Choe HS, Lee DS, Yoo JM, Lee SJ. Is absence of hydronephrosis a risk factor for bleeding in conventional percutaneous nephrolithotomy? Urology journal. 2020 Jan 26; 17(1):8-13. https://doi. org/10.22037/uj.v0i0.4826.

4. Wang S, Zhang $Y$, Zhang $X$, Tang $Y$, Xiao B, Hu W, Chen $\mathrm{S}$, Li J. Tract dilation monitored by ultrasound in percutaneous nephrolithotomy: Feasible and safe. World journal of urology. 2020 Jun; 38(6):1569-76. https://doi.org/10.1007/s00345-019-02876-7.

5. Zhang B, Xie H, Hu Y, Liu C. The visual percutaneous nephrolithotomy versus the conventional percutaneous nephrolithotomy in treatment for renal stone. Minerva urologica e nefrologica $=$ The Italian journal of urology and nephrology. $2019 \mathrm{Jul} 8$; 71 (6):62735. https://doi.org/10.23736/s0393-2249.19.03465-9.

6. Gadzhiev N, Malkhasyan V, Akopyan G, Petrov S, Jefferson F, OkhunovZ. Percutaneous nephrolithotomy for staghorn calculi: Troubleshooting and managing complications. Asian journal of urology. 2020 Apr 1; 7(2):139-48. https://doi.org/10.1016/j.ajur.2019.10.004.

7. Falahatkar R, Shahraki T, Falahatkar S, Esmaeili S, Mashouf $P$. Evaluating outcomes of complete supine percutaneous nephrolithotomy for staghorn vs multiple non-staghorn renal stones: A 10-year study. World Journal of Urology. 2021 Jan 5:1-7. https://doi. org/10.1007/s00345-020-03563-8.

8. Levy MM, Evans LE, Rhodes A. The surviving sepsis campaign bundle: 2018 update. Intensive care medicine. 2018 Jun; 44(6):925-8. https://doi. org/10.1007/s00134-018-5085-0.

9. Wang $\mathrm{S}$, Yuan P, Peng E, Xia D, Xu H, Wang S, Ye Z, Chen Z. Risk factors for urosepsis after minimally invasive percutaneous nephrolithotomy in patients with preoperative urinary tract infection. BioMed research international. 2020 Jan 2; 2020. https://doi. org/10.1155/2020/1354672. 
10. Loftus CJ, Hinck B, Makovey I, Sivalingam S, Monga M. Mini versus standard percutaneous nephrolithotomy: The impact of sheath size on intrarenal pelvic pressure and infectious complications in a porcine model. Journal of endourology. 2018 Apr 1; 32(4):3503. https://doi.org/10.1089/end.2017.0602.

11. Othman KA, Gazala SG, Jawad NR. Factors Affecting Post Nephrostomy Removal Urinary Leakage after Percutaneous Nephrolithotomy (PCNL). Diyala Journal of Medicine. 2020 Dec 15; 19(2):165-73.

12. Zhu L, Jiang R, Pei L, Li X, Kong X, Wang X. Risk factors for the fever after percutaneous nephrolithotomy: A retrospective analysis. Translational andrology and urology. 2020 Jun; 9(3):1262. https://dx.doi. org/10.21037\%2Ftau.2020.03.37.

13. Kim HY, Choe HS, Lee DS, Yoo JM, Lee SJ. Is absence of hydronephrosis a risk factor for bleeding in conventional percutaneous nephrolithotomy? Urology journal. 2020 Jan 26; 17(1):8-13. https://doi. org/10.22037/uj.v0i0.4826.

14. Wang S, Zhang Y, Zhang X, Tang Y, Xiao B, Hu W, Chen $S$, Li J. Tract dilation monitored by ultrasound in percutaneous nephrolithotomy: Feasible and safe. World journal of urology. 2020 Jun; 38(6):1569-76. https://doi.org/10.1007/s00345-019-02876-7.

15. Meng $X$, Bao J, Mi Q, Fang $S$. The analysis of risk factors for hemorrhage associated with minimally invasive percutaneous nephrolithotomy. BioMed research international. 2019 Jan 30; 2019. https://doi. org/10.1155/2019/8619460.

16. Pimratana C, Wijitsettakul U, Chuenganuwat $P$. Outcomes of artificial hydronephrosis in ultrasound guided percutaneous nephrolithotomy in lateral position in non-hydronephrotic renal stones. Siriraj Medical Bulletin. 2020 Oct 1; 13(4). https://doi. org/10.33192/Simedbull.2020.32.
17. Dagrosa $L$, Moses R, Pais V. Incidence and implications of silent hydronephrosis following percutaneous nephrolithotomy. Clinical nephrology. 2017; 87(1):29.

18. Kadihasanoglu M, Erkan E, Yucetas U, Culha G, Toktas $\mathrm{G}$, Atahan O. Does preoperative hydronephrosis affect the stone-free rate of micro-percutaneous nephrolithotomy?. Archivos espanoles de urologia. 2019 May 1; 72(4):406-14.

19. Basnet RB, Shrestha A, Shrestha PM, Joshi BR. Risk factors for postoperative complications after percutaneous nephrolithotomy. Journal of Nepal Health Research Council. 2018 Mar 18; 16(1):79-83.

20. Balaji A, Chellapandian R. Outcome and complications of PCNL-A single centre experience.

21. Dwivedi D, Sud S, Singh S, Kumar M. Postoperative pneumomediastinum with bilateral pneumothorax following percutaneous nephrolithotomy. Indian Journal of Respiratory Care. 2020 Jan 1; 9(1):113.

22. Kizilay F, Akcam TI, Kalemci S, Simsir A, Turna B, Kavurmaci O, Cagirici U, Nazli O, Ozyurt C, Cureklibatir I. Evaluation of thoracic complications after urological operations: A Single-center Experience/ Urolojik Operasyonlar Sonrasi Ortaya Cikan Torasik Komplikasyolarin Degerlendirilmesi: Tek-merkez Deneyimi. Journal of Urological Surgery. 2019 Sep 1; 6(3):184-90.

23. Zhu A, Weiner AB, Nadler RB. Radiographic hemithorax white-out following percutaneous nephrolithotomy. Urology case reports. 2018 Mar; 17:1. https://dx.doi. org/10.1016\%2Fj.eucr.2017.12.002.

\section{AUTHORSHIP AND CONTRIBUTION DECLARATION}

\begin{tabular}{|c|c|c|c|}
\hline No. & Author(s) Full Name & Contribution to the paper & Author(s) Signature \\
\hline 1 & Fakhir Yousuf & Data analysis, Data collection. & 0 \\
\hline 2 & Salman el Khalid & $\begin{array}{l}\text { Topic selection and data } \\
\text { collection, Abstract and recording. }\end{array}$ & \\
\hline 3 & $\begin{array}{l}\text { Abdul Wasy Mahmood } \\
\text { Zafar lqbal }\end{array}$ & $\begin{array}{l}\text { Data analysis, Data collection, } \\
\text { Found additional literature for } \\
\text { information, Data composing. } \\
\text { Data analysis, Data collection. }\end{array}$ & \\
\hline 5 & Waqar Hassan & Data collection. & \\
\hline 6 & $\begin{array}{l}\text { Shakeel Haseeb } \\
\text { Uddin Siddique }\end{array}$ & Data collection. & sandual \\
\hline
\end{tabular}

